\title{
Innovation Ability Cultivation of Graduate Students of Computer Science and Technology under the Background of Science and Education Integration
}

\author{
Jing Chen, Meihong Yang, Ying Guo, Hu Zhang \\ Shandong Provincial Key Laboratory of Computer Networks, Shandong Computer Science Center (National Supercomputer \\ Center in Jinan), Qilu University of Technology (Shandong Academy of Sciences), Jinan, China \\ Email: jingchen94@163.com
}

How to cite this paper: Chen, J., Yang, M. H., Guo, Y., \& Zhang, H. (2021). Innovation Ability Cultivation of Graduate Students of Computer Science and Technology under the Background of Science and Education Integration. Advances in Applied Sociology, 11, 618-625.

https://doi.org/10.4236/aasoci.2021.1112052

Received: October 27, 2021

Accepted: December 11, 2021

Published: December 14, 2021

Copyright $\odot 2021$ by author(s) and Scientific Research Publishing Inc.

This work is licensed under the Creative Commons Attribution International License (CC BY 4.0).

http://creativecommons.org/licenses/by/4.0/

\begin{abstract}
Innovation based on science and technology is one of the important national strategies. This paper analyzes the problems of the current graduate students of computer science and technology in China, and proposes a new mode of the cultivation of graduate students' innovation ability under the background of science and education integration, including the mode of diversified cultivation, gradient and hierarchical training plan and the multiple ways of cultivating the innovative ability of graduate students by case practice, research project training and engineering practice. This new mode studied through research analysis, exploratory practice and comparative methods can improve the innovation ability of graduates to meet the needs of modern information industry and high-tech development. Simultaneously, it can also realize the critical innovation to promote scientific and technological development and cultivate professionals in various technical fields.
\end{abstract}

\section{Keywords}

Innovation Ability Cultivation, Science and Education Integration,

Diversified Cultivation, Gradient and Hierarchical Training

\section{Introduction}

The Ministry of Education of the People's Republic of China issued the opinions on strengthening the training of practical and innovative ability of graduate students by science and education integration. Compared with undergraduate edu- 
cation, graduate students should have better innovation abilities and produce the high-level research results ( $\mathrm{Yu}, 2021)$. There exist some problems in the cultivation of innovation ability, such as lack of awareness of independent innovation, imperfect innovation practice mechanism and weak academic atmosphere (Song \& Zhao, 2021). The innovation ability cultivation of graduate students is proposed based on research projects (Li et al., 2021). The students' cultivation of innovation ability on demand guide is proposed to promote the development of the chemistry and chemical engineering subject (Wang et al., 2021). A systematic cultivation mechanism on the ability of practice and innovation ability of professional graduate students is studied, which forms the "five-in-one" mechanism including training target, training object, training subject, training content and training evaluation (Meng \& Liu, 2021). The problem of graduate students' innovation ability in domestic universities in china was analyzed and it was concluded that most researches in recent years are qualitative (Lin \& Wang, 2019). The effect of the mathematical modeling competition on the graduate students' innovation ability was discussed and graduate students' insight, imagination, logical thinking were emphasized to improve graduate students' ability of solving problems ( $\mathrm{Li}$, 2016). The main problems and influence factors were analyzed, and then the relevant countermeasures of graduate students' innovation ability majoring in management science and engineering were put forward (Fu, 2018). A teaching reform of postgraduate innovative practice education driven by subject competition is proposed to improve the quality and efficiency of discipline competition, which builds a more efficient assessment process and optimizes the discipline competition resources (Li \& Pan, 2021). Although domestic universities actively cultivate the innovative ability of graduate students by means of scientific research projects, discipline competitions and university-industry cooperation, there are still some gaps (Yin, 2021), mainly reflected in the following aspects: 1 ) There are a lot of follow-up studies, which lack innovation on core technologies to train professionals in short supply to solve problems in key technical fields; 2) It lacks interdisciplinary team construction. The single tutor training method is difficult to meet the needs of society, so students' initiative innovation consciousness is not strong affecting the training of postgraduate innovation ability; 3) School-enterprise cooperation lacks long-term cooperation mechanism. It is difficult to dig out deep-rooted problems in the project, which leads to the limited training of graduate students' innovation ability and achieves little innovation results.

Considering both graduate students' development and national demands, a cultivation program is planned to improve the students' innovation ability of scientific research and engineering practice. Through the reform of graduate students' cultivation program for computer science and technology major, the cultivation of graduate students with high innovative ability in scientific theory and engineering practice not only meets the national needs for professional and technical personnel, but also has practical significance in improving teaching quality. 


\section{Needs of Cultivating the Innovation Ability of Graduate Students of Computer Science and Technology}

With the change of international competitive environment and the development of China's economy, scientific and technological innovation has become a national development strategy. Training innovative and high-quality professionals to meet the diversified development needs of the society has become an important goal of high-level education. Only with a large number of innovative talents can we stand out in the fierce international competition (Wen, 2013). Under the background of "double first-class" and "striving for first-class" construction, the innovation potential of graduate students is stimulated (Chen \& Li, 2021). How to cultivate the innovation ability of graduate students of computer science and technology to meet social needs is of great importance.

\subsection{National Innovative Development Requirement}

Graduate education is a high-level education to reserve innovative talents, whose key goal is to cultivate the innovative ability of graduate students. The Ministry of Education, the National Development and Reform Commission, Ministry of Finance issued "the opinions on speeding up the reform and development of graduate education", which points out that enhancing the cultivation of graduate students' practice innovation ability is still one of the important tasks of graduate education in 2020. Especially for those majoring in computer science and technology, the training process is characterized with interdisciplinary integration, rapid iteration and updating of professional technology (Wang \& Yang, 2015), which puts forward higher requirements for the training of graduate students' innovative ability.

\subsection{Important Path to Keep up with the Times}

Different from undergraduate education, the innovation ability education of graduate students is not simply practice skills, but the ability of independently engaging in scientific research and creatively using the learned knowledge in the industry. There are differences in the cultivation of students' scientific research and innovation ability in foreign countries. German universities adopt the "apprenticeship" cultivation mode, in which teachers and students are closely connected. Students participate in the research projects of supervisors and achieve strong innovation ability through scientific research practice. The United States has a mature system for cultivating the innovation ability of graduate students', which combines discussion, practice and teaching to strengthen students' scientific research ability. Through industry-university-research cooperation, it provides abundant opportunities for scientific research practice and cultivates students' spirit of scientific exploration. The government-industry-university research cooperation mode adopted by Japanese universities provides a good platform for the cultivation of graduate students' innovation ability. Local governments provide financial support for universities, and enterprises provide research directions and assist universities to test and revise research results in 
practice. The supervisors in universities are responsible for leading graduate students to directly participate in enterprise projects.

\section{Problems of Cultivating the Innovation Ability of Graduate Students of Computer Science and Technology in China}

Although the scale of graduate students in China has become second only to that of the United States by 2020, domestic universities actively cultivate the innovative ability of graduate students by means of scientific research projects, discipline competitions, school-enterprise cooperation, etc. There are still some gaps.

1) Lack of New Content: At present, the training method of graduate students is mainly to follow the guidance of the tutors, which lacks the content innovation and the key technologies, making it difficult to cultivate professionals in short supply. Especially, computer science and technologies change very fast and some of tutors can't keep up with these changes.

2) Lack of Interdisciplinary Team Construction: The single tutor training mode is difficult to meet the national and industry needs. Students' innovation consciousness is not strong, and the supervised graduate students do not have diversified knowledge systems, which affects the cultivation of graduate students' innovation ability.

3) Limitation of Innovation Ability of Graduate Students: School-enterprise cooperation lacks long-term cooperation mechanism, and it is difficult to dig out deep-seated problems in the project, resulting in low innovation level, limited energy of enterprise mentors, and difficult to achieve innovation results.

\section{Reform Measures to Improve the Innovation Ability of Graduate Students of Computer Science and Technology}

\subsection{Diversified Cultivation Mode}

The study direction and goal of graduate students in school should be designed and planned according to their' future employment direction and further study demands combined with students' personality, current advantages and future planning. The demand trends for various professionals should be found by analyzing the development of industries. Furthermore, the cultivation plan matches graduate students' development goals with industry needs (Zhu, 2018). In the first year of graduate students' study, it can guide their future development direction and course selection. The relative innovation exercises, case studies and research practices can be designed according to the cultivation plan. Thus, a diversified innovation ability cultivation mode is constructing through combining with graduate students' course selection, scientific research and engineering practice.

\subsection{Gradient Innovation Ability Cultivation}

A gradient and hierarchical cultivation plan is formulated according to industry demands, graduate students' development direction and the diversified cultiva- 
tion mode of the innovation ability. The contents and objectives of improving the graduate students' innovation ability are made in stages, which mainly designs the promotion of graduate students' basic and multi-category personalized innovation ability. The cultivation plan of improving of graduate students' innovation ability can be gradually revised by monitoring the development and change of industrial needs, students' development and demand in this process, which can stimulate the enthusiasm and creativity of graduate students.

\subsection{Interdisciplinary Mentor Team Construction}

Generally, graduate students carry out scientific research within the tutor's research group, which causes that they lack the knowledge related to other disciplines. However, the current research projects become large in scale and involve many disciplines with the extensive application of information technology in various fields. Along with the expansion of graduate enrollment, the single tutor cultivation mode is difficult to meet the rapid development needs of the information industry. An interdisciplinary tutor team focusing on cloud computing, big data, artificial intelligence and high-performance computing should be established to guide graduate students to participate in the important interdisciplinary projects to improve their research and innovation capabilities.

\subsection{Construction of Graduate Students' Innovation Platform}

The heterogeneous resources can help graduate students to carry out the scientific research and engineering practice based on super-computing platform. The high-level interdisciplinary mentor team can guide graduate students to participate in the national research projects. Graduate students can also dig out the deep-seated problems of industrial projects and solve the difficulties of the cooperative enterprises. Therefore, the innovation ability of graduate students is driven by scientific research projects and industrial demands.

\subsection{Summary}

The above-mentioned measures are relative. Based on the graduate students' Innovation platform, graduate students of computer science and technology should be cultivated by adopting a diversified cultivation mode under a plan of gradient innovation ability cultivation and the introduction of interdisciplinary mentor team construction.

\section{Concrete Implementation of Improving the Innovation Ability of Graduate Students of Computer Science and Technology}

The framework of the cultivation plan of graduate students of computer science and technology is shown in Figure 1 based on the analysis of the reform measures in section 4, which involves in the platform with rich resources, the national 


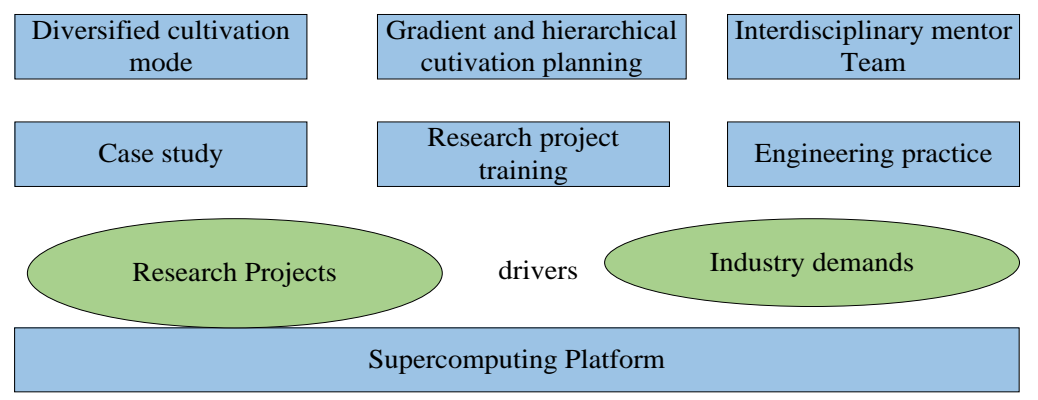

Figure 1. Cultivation of graduate students' innovation ability.

scientific research projects and the enterprises demands, the diversified cultivation mode, the interdisciplinary mentor team through case studies, scientific research project and engineering practice. Based on the supercomputing platform, the research projects and industry demands are collected for guiding the innovation cultivation of graduate students, which can provide more case studies, research project training and engineering practices to implement the diversified cultivation mode, the gradient innovation ability cultivation and the construction of interdisciplinary mentor team construction.

\subsection{Implementation Plan}

The team leader coordinates the overall layout and establishes different groups according to the cultivation framework. Each group separately carries out the formulation of the diversified innovation ability of graduate students, the hierarchical training planning, the construction of interdisciplinary mentor team. And case studies, scientific research project training and engineering practice are designed to improve the innovation ability of graduate students of computer science and technology.

The cultivation process of graduate students of computer science and technology is monitored, where the promotion effect of graduate students can be traced and the cultivation plan can be continuously adjusted according to the change of society and students' demands.

\subsection{Implementation Method}

1) Research analysis method: The cultivation plans of the innovation ability of graduate students in Chinese universities are investigated and analyzed, which helps the universities design the diversified cultivation plan of innovation ability of graduate students combined with industrial demands.

2) Exploratory practice: The diversified cultivation plan of graduate students' innovation ability is applied to the process of graduate students' cultivation, and the progress and effect of the practical teaching reform are explored in stages.

3) Follow-up and comparative method: The effect of improving the innovation ability of graduate students was tracked and monitored throughout the whole process. After graduate students' employment, it is analyzed that the innovation ability of postgraduate students matches with the position of enterpris- 
es according to the feedback of students and enterprises.

\section{Conclusion}

To improve the national competitiveness, the cultivation of innovative professionals is of great importance. This paper proposes a cultivation framework of graduate students of computer science and technology driven by the platform with rich resources, the scientific research projects and the enterprises demands, which involves in the diversified cultivation mode and the interdisciplinary mentor team to improve the innovation ability of graduate students' innovative ability of computer science and technology. Hopefully, it can contribute to the education reform of graduate students of computer science and technology.

\section{Acknowledgements}

This work was partly supported by Shandong Provincial Undergraduate University Teaching Reform Research Project (No. Z2020042), Qilu University of Technology (Shandong Academy of Sciences) Science, Education and Industry Integration Innovation Pilot Project (No. 2020KJC-ZD01), and Shandong Provincial Teaching Reform Research Project (No. SDYJG21177).

\section{Conflicts of Interest}

The authors declare no conflicts of interest regarding the publication of this paper.

\section{References}

Chen, L. W., \& Li, H. B. (2020). Research on the Innovation Ability of Graduate Students. Chinese Adult Education, No. 3, 45-49.

Fu, M. J. (2018). Research on the Training of Graduate Students' Practice and Innovation Ability in Management Science and Engineering. In W. Striełkowski (Eds.), Proceedings of the 2018 8th International Conference on Social Science and Education Research (pp. 344-348). Atlantis Press. https://doi.org/10.2991/sser-18.2018.72

Li, C., \& Pan, H. (2021). Research on the Teaching Reform of Postgraduate Innovative Practice Education Driven by Subject Competition. Theoretical Research and Practice of Innovation and Entrepreneurship, 5, 96-98.

Li, G., Jiang, L., Ding, R. Q. et al. (2021). Research on Improving the Innovation Ability of Mechanical Graduate Students Based on Scientific Research Projects. Journal of Higher Education, 15, 51-54.

Li, Z. Q. (2016). Explore the Training Mode of Innovative Ability of Graduates in the Platform of Graduate Mathematical Modeling Competition. In 2016 International Conference on Education Science and Education Management (pp. 141-144). Destech Publications.

Lin, L. P., \& Wang, Y. (2019). Research on the Innovation Ability of Postgraduates in Local Universities. In T. Hauer (Ed.), Proceedings of the 2019 5th International Conference on Social Science and Higher Education (pp. 223-226). Atlantis Press. https://doi.org/10.2991/icsshe-19.2019.57

Meng, Z. J., \& Liu, Y. J. (2021). Study on the Systematic Cultivation of Practical Innova- 
tion Ability of Professional Degree Postgraduates. Journal of Hubei Normal University (Philosophy and Social Science), 41, 105-109.

Song, C. H., \& Zhang, L. (2021). Research on the Cultivation of Postgraduates' Innovative Ability in Local Universities in the Background of Modernization of Higher Education. Journal of Jilin Institute of Chemical Technology, 38, 56-59.

Wang, H., \& Yang X. Y. (2015). Analysis on quality Control of Key Links of full-time Master of Engineering Training. Heilongjiang Education (Higher Education Research and Evaluation), No. 1, 70-71.

Wang, L. Y., Zhao, M., Zhao, B. et al. (2021). Study on the Chemistry and Chemical Engineering Subject Students' Cultivation of Innovation Ability on Demand Guide. Shandong Chemical Industry, 50, 215-216.

Wen, K. (2013). Research on Biogenesis and Innovation Need to Renew Culture and Culture. Chinese Journal of Social Science, A07.

Yin, B. (2021). Exploration and Practice on the Cultivation of Postgraduates' Scientific Research and Innovation Abilities in the Context of "Double-First-Class" Construction. Computer Era, No. 6, 68-70, 73.

$\mathrm{Yu}$, W. J. (2021). The Implementation Approach of Science and Education Integration Training Based on Improving Graduate Students' Scientific Research Innovation Ability. University Education, No. 4, 25-28.

Zhu, F. Z. (2018). The Exploration of Cultivating Graduate Students' Scientific Research Innovation Ability with Subject Research-Oriented-A Case Study of Heilongjiang University. Heilongiiang Education (Higher Education Research and Evaluation), No. 1, 63-64. 